УДК 316

$10.17213 / 2075-2067-2020-4-150-158$

\title{
СОЦИАЛЬНАЯ РЕПУТАЦИЯ РОССИЙСКОГО МАЛОГО БИЗНЕСА И ПЕРСПЕКТИВЫ ЕГО РАЗВИТИЯ В ПОСТКОРОНАВИРУСНОМ МИРЕ
}

\author{
(C) 2020 г. К. А. Чернов
}

\section{Южно-Российский государственный политехнический университет (НПИ) имени М. И. Платова, г. Новочеркасск, Россия}

Целью исследования является сочиологическое изучение противоречивых аспектов формирования и развития социальной репутации малого бизнеса в современном российском обществе, а также особенностей и перспектив его развития в условиях непростых социально-экономических реалий, ещче более осложнившихся в период пандемии коронавируса.

Методологическую базу исследования представляют идеи и теории, сложившиеся в границах сочиологической теории, позволяющей объяснить сложности становления социологии репутаций, а также противоречивые аспекты развития и восприятия бизнесдеятельности в России. В работе анализируется потенциал теоретических идей зарубежных исследователей (Т. Парсонса, П.-М. Шовена, М. Айзенеггера) и российских ученых (А. В. Овруикого, Ф.В. Малахова и др.) в области изучения феномена репутации в современном обществе.

Результаты исследования. Сложный путь институционализации малого бизнеса в постсоветской России в условиях негативного отношения к бизнесу со стороны населения, сформировавшегося еще на этапе перехода к рыночным отношениям на рубеже XX-XXI вв., принес свои плоды к началу 2020 года. Отношение к малому бизнесу в России стало более лояльным, доверительным. Основой его положительной репутации в обществе, согласно данным сочиологических опросов, стала сочиальная полезность бизнес-деятельности. Однако сильный удар, нанесенный пандемией коронавируса, остро поставил перед оставиимися в малом бизнесе предприятиями вопрос выживания. Это может негативно сказаться на его сочиальной репутации ввиду значительного сокращения сектора малого бизнеса в экономической структуре общества и, следовательно, снижения его социальной полезности.

Перспективу исследования составляет дальнейшая соииологическая рефлексия ситуации, в которой разворачивается деятельность малого бизнеса и экспертно-диагностический анализ перспективных сиенариев его развития в посткоронавирусном мире.

Ключевые слова: социальная репутаџия; бизнес; мальй бизнес; репутационные оценки; пандемия коронавируса; посткоронавирусный мир.

\section{SOCIAL REPUTATION OF RUSSIAN SMALL BUSINESS AND PROSPECTS FOR ITS DEVELOPMENT IN THE POST-CORONAVIRUS WORLD}

\section{(C) 2020 K. A. Chernov}

\section{Platov South Russian State Polytechnic University (NPI), Novocherkassk, Russia}

The purpose of the study is to study the socio-logical aspects of the formation and development of the social reputation of small business in modern Russian society, as well as the peculiarities 
and prospects of its development in the context of difficult socio-economic realities, which were even more complicated during the coronavirus pandemic.

The methodological base of the research is represented by ideas and theories that have developed within the framework of sociological theory, which allows explaining the complexities of the formation of the sociology of reputations, as well as the contradictory aspects of the development and perception of business activities in Russia.The paper analyzes the potential of theoretical ideas of foreign researchers (T. Parsons, P.-M. Chauvin, M. Aisenegger) and Russian scientists (A. V. Ovrutsky, F. V. Malakhov, etc.) in the field of studying the phenomenon of reputation in modern society.

The results of the study. The difficult path of institutionalizing small business in post-Soviet Russia under the conditions of a negative attitude towards business on the part of the population, which was formed at the stage of transition to market relations at the turn of the XX-XXI centuries, bore fruit by the beginning of 2020. The attitude towards small business in Russia has become more loyal and trusting. The basis of his positive reputation in society, according to opinion polls, was the social usefulness of his business activities. However, the severe blow from the coronavirus pandemic has sharply raised the question of survival for the remaining small businesses. This can negatively affect its social reputation due to a significant reduction in the small business sector in the economic structure of society and, consequently, a decrease in its social utility.

The prospect of the study is a further sociological reflection of the situation in which the activities of small business and expert-diagnostic analysis of promising scenarios for its development in the post-coronavirus world are developing.

Key words: social reputation; business; small business; reputation scores; coronavirus pandemic; post-coronavirus world.

Введение. Обсуждать вопросы, связанные с социальной репутацией бизнеса в России (и малого в том числе) имеет смысл в широком социальном контексте, а этот контекст определяется постановкой ключевого вопроса: есть ли вообще в современной России репутация как явление, детерминирующее социальные практики и социокультурное развитие? Не отодвинут ли этот общественный моральный регулятор на «задворки» социальных детерминант? В. Лейбин, к примеру, полагает, что «в современной России репутаций нет» при наличии парадокса, выражающегося в одновременном существования в пластах российской культуры и массового сознания высоких образцов общенациональной общественной репутации, и очевидного их отсутствия в политической реальности [1].

Иными словами, о социальной репутации в России можно говорить на абстрактном уровне, привлекая ментальные особенности и исторически сложившиеся образцы, и на уровне реалий современного времени, разворачивающихся для каждой отдельно взятой социальной сферы, отрасли, организации в собственной логике, но с учетом социальных закономерностей, учитывающих историко-культурные традиции и траектории общественной динамики.

В этой связи невысокие показатели социальной репутации малого бизнеса в России естественным образом вызывают интерес в научной среде при том, что ситуация в последнее десятилетие более положительная в этом плане, нежели на рубеже столетий и в начальный период постсоветской истории российского государства [2]. Этот интерес возрастает по мере роста престижа бизнес-деятельности и профессии бизнесмена в молодежной среде [3], что актуализирует потенциал социологической теории, как классической, так и неклассической в объяснении противоречивых аспектов развития и восприятия бизнес-сферы в российском обществе, а также особенностей формирования репутационного капитала малого бизнеса в условиях непростых социально-экономических реалий, еще более осложнившихся в период пандемии коронавируса. 
Малый и средний бизнес, согласно данным ООН, составляют порядка $90 \%$ всего бизнеса в мире с долей в $50 \%$ в мировом ВВП, и, естественно, что удар, нанесенный коронавирусной ситуацией по этому сектору экономики, вызвал волну обсуждений относительно его судьбы не только в период коронавируса, но и в посткоронавирусный период [4], поскольку очевидно, что постпандемический мир уже не будет прежним, что произошел сдвиг в массовом сознании, нуждающийся в научном осмыслении [5]. Более того, эта ситуация ярко продемонстрировала шаткость той экономической платформы, на которой базируются современные социально-экономические процессы и отношения, а также опасность глобализации, в кратчайший период создавшей рискогенную зону на планетарном уровне ввиду неимоверно быстрого распространения вируса COVID-19 по глобализационным каналам.

Социальная репутация в границах теоретического дискурса. Еще Т. Парсонс выделил в качестве важнейшего элемента комплекта посредников в зоне взаимопроникновения между социальной и культурной системами репутацию [6]. Между последней и социальным престижем имеются, согласно стратификационной теории Парсонса, модельные различения [7]. И на примере расхождений в репутации и престиже бизнеса в России мы это прекрасно наблюдаем. Закономерно возникает вопрос о причинах этих различий. Ответ на него следует искать в самой теории социальной репутации, в социальной природе данного явления.

Несмотря на то, что в современной социологии представлены теоретические подходы и концепции, содержащие анализ репутации как социального явления, как категории социологического анализа, социология репутаций как область исследования, по свидетельству П.-М. Шовена, сравнительно новая и еще не характеризующаяся четкой структурой и доверием среди социологов, полагающих, что само понятие «репутация» несет в себе заряд «субъективного» и «второстепенного», т.е. вторичных репрезентаций, формирующихся на основе позиций и мнений относительно действий и поступков людей [8].
Тем не менее, постепенно репутация как предмет социологического дискурса все чаще попадает в фокус социологического знания, справедливо занимая на современный день значимое в нем место. Поле дискуссии достаточно обширно. Так, П.-М. Шовен, стремясь дать определение феномену репутации, отталкиваясь от этимологии данного слова (от латинского reputatio (оценка)) и рассматривая репутацию в самом общем виде как продукт совокупности оценок, задается вопросом о природе связи между репутацией и оценкой, и, имея собственную позицию по данному вопросу, дает определение репутации, активно используемое сегодня социологами. Репутация, согласно определению П.-М. Шовена, есть «социальная репрезентация, разделяемая большинством, носящая временный и локальный характер, ассоциирующаяся с определенным именем и основывающаяся на более или менее влиятельных и более или менее формализованных социальных оценках» [8].

Таким образом, П.-М. Шовен выделяет две ключевые характеристики такого феномена, как репутация: разделяемость большинством и персонификация, связь с именем собственным. Проще говоря (и нам это простое определение импонирует), репутация - это «мнение, которое уже создано третьими лицами и на которое люди опираются, когда выносят суждения или принимают решения» [8].

Интерес представляет подход М. Айзенеггера, включившего в контекст исследования социальной репутации концепт доверия как определяющий в системе социальных коммуникаций, поскольку само доверие базируется на репутационных оценках, в свою очередь детерминирующих выбор в том или ином поле деятельности (экономическом, политическом) [9]. Репутационная оценка складывается из трех составляющих: функциональной (компетентность субъекта деятельности в реализации задач и функций, соответствующих конкретному виду деятельности), социальной (социальная ориентация на общественное благо реализуемой деятельности, ее социальная полезность и соответствие общественным нормам и ценностям) и эмоциональной (личностные характеристики субъекта деятельности: привлекательность, неповторимость, уникальность и др.). 
Все три составляющие, которые представляют собой по сути индикаторы измерения репутации того или иного субъекта, оказывают комплексное влияние на формирование репутационных оценок, но в конфигурации этих измерителей тот или иной индикатор в каждом отдельном случае может стать доминантным, определяя характер и динамику репутации субъекта. Так, в сфере бизнес-деятельности (и не только) эмоциональная репутация может сыграть определяющую роль в формировании репутации бизнес-субъекта. Это особенно характерно для обществ, ментально ориентированных на персонификацию при оценке деятельности тех или иных социальных субъектов, институтов, организаций и т.д., и в современной реальности феномен персонификации не утратил своей актуальности [10]. Хорошо известно, что российское общество относится именно к такого рода обществам, что наглядно проявляется на примере репутационных оценок, формировавшихся по отношению к политическим лидерам государства (царям, императорам, вождям, президентам) и власти в целом [11].

Идеальная конструкция положительной репутации субъекта, отталкиваясь от теории Айзенеггера, включает в себя способность успешно решать функциональные задачи, при этом учитывать принципы социальной ответственности и обладать эмоционально привлекательными чертами и свойствами, создающими отличный от других субъектов в том или ином пространстве деятельности образ [9]. Предложенные данным ученым измерители репутации с успехом можно применить и к бизнес-организациям, бизнес-сообществам, бизнес-сфере, учитывая такие параметры еe формирования, как функциональная эффективность, социальная ориентированность/ответственность и эмоциональная привлекательность.

Российские социологи также прилагают значительные усилия в концептуализации феномена репутации, изучении его как с позиций личности, так и организации [12]. Во втором случае принято говорить о деловой репутации, анализ которой проводится в рамках изучения деловых организаций, как правило, в бизнессфере, а под деловой репутацией социологи предлагают понимать «обезличенное коллективное представление о прошлых действиях и результатах работы компании, основанное на оценке социальной деятельности организации, среди представителей заинтересованных в ее работе групп» [13].

Представлены в научном поле также попытки распредметить понятие репутации c позиций междисциплинарного подхода. А.В. Овруцкий с опорой на данный подход рассматривает репутацию как ресурс, локализованный в объектах репутационного менеджмента, репрезентация которого отражается в форме социального представления в зависимости от индивидуального и массового сознания стейкхолдеров [14].

Не вдаваясь дальше в теоретические лабиринты исследования социальной репутации, отметим вслед за П.-М. Шовеном, что возникающие вопросы по поводу такого феномена, как репутация, разнообразны, различны, некоторые из них пересекаются между собой, повторяются, принципиально нового не содержа в себе [8], а потому перейдем к практическим аспектам, связанным с реалиями функционирования малого бизнеса в России, связанным с его репутационным капиталом, сформировавшимся за перестроечный и постсоветский период в обществе, не знавшем прежде рыночных отношений, не готовом к ним и так и не сумевшем создать цивилизованной рыночной среды, адекватной принципам здоровой конкуренции и социальной ответственности [15].

Российский малый бизнес в условиях современных реалий и вызовов «коронавирусного» мира. Удивительно складывается ситуация с развитием бизнеса в России и, в частности, малого и среднего. Весьма сложным можно назвать путь малого бизнеса в постсоветской российской реальности к своей институционализации и восстановлению репутации, изначально испорченной самой стратегией формирования бизнеса, прежде всего, крупного, в постсоветской России, его связью (и по сей день) с властью, коррупционными схемами деятельности, преступным происхождением самого бизнес-каптала и т.д. [16]. Малым и средним бизнес-предприятиям в условиях жесткого неприятия таким образом формировавшегося бизнеса и представления о нем среди российского населения приходилось нелегко, и ко всему 
прочему периодические кризисы (1998, 2008, 2014 гг.) тормозили его развитие, вынуждали использовать «теневые» схемы и механизмы деятельности, чтобы выжить в турбулентном мире российского рынка. И, тем не менее, к началу 2020 года малому бизнесу удалось сформировать свое, достаточно неплохое, «имя», о чем говорят данные социологических исследований о желающих заниматься бизнесом, о престижности профессии бизнесмена и, что главное, об оценке малого бизнеса с точки зрения пользы, который он приносит населению страны [2].

Однако очередной кризис, на этот раз вызванный не экономическими причинами, но событиями, имеющими далеко идущие экономические последствия, угрожает гибелью тем «росткам» малого бизнеса, в том числе и репутационным, которые имели место быть до начала пандемии коронавируса. Об этом писали эксперты в разгар коронавирусной инфекции, указывая на то, что самый сильный удар пришелся на сектор малого и среднего предпринимательства, когда упал спрос на услуги ресторанного, гостиничного бизнеса, индустрии красоты, спорта и туризма, магазинов розничной торговли, а это поставило остро вопрос банкротства бизнеспредприятий указанных направлений бизнесдеятельности [17].

При всем том, что государство отреагировало на ситуацию с пандемией COVID-19 достаточно оперативно в виде принятия мер по поддержке малого и среднего бизнеса в России, данные исследования Общероссийского народного фронта, «ОПОРы России» и Торгово-промышленной палаты (ТПП) показали, что далеко не все организации этого сектора экономики, которые нуждались в поддержке, попали под ОКВЭД (общероссийский классификатор видов экономической деятельности), определивший перечень пострадавших отраслей (так считают 48\% опрошенных) [4]. Безусловно, общественность озабочена критической ситуацией в сфере развития малого и среднего бизнеса, и уже идет обсуждение стратегий и вариантов возвращения в бизнес тех организаций и предприятий, которые вынуждены были «покинуть» сферу бизнеса в период пандемии COVID-19, но хотели бы вернуться в бизнес, а их, согласно данным Общероссийской общественной организа- ции малого и среднего предпринимательства «Опора России», порядка 80\% [18]. Данной организацией было внесено предложение создать некий добровольный реестр «предпринимателей запаса» - по аналогии с офицерами запаса Министерства обороны РФ.

Ситуация, вызванная пандемией COVID-19, обозначила не только критические точки и рискогенные зоны бизнес-деятельности, но и перспективные направления развития деятельности бизнес-организаций. Так, данные ряда международных и российских исследовательских проектов (StartupBlink, Euromonitor, Институт анализа инвестиционной политики и др.) определили среди наиболее актуальных и востребованных направлений для развития малого бизнеса такие, как профилактика распространения вирусной инфекции, диагностика заболевания, диагностические процедуры в области оценки информации и анализа больших данных, высокотехнологичные разработки, адаптивные механизмы в условиях карантина и самоизоляции [4]. Было также отмечено, что в кризисных условиях пандемии коронавируса только те бизнесмены удержались «на плаву», которые вовремя отреагировали на изменившуюся конъюнктуру рынка и адаптировались к ней, перестроив свою деятельность в адекватном сложившейся ситуации направлении [19].

Выводы. Итак, в современной ситуации перед малым бизнесом в России остро стоит не столько вопрос репутации, отношения к бизнесменам, к их деятельности и продукции, сколько вопрос выживания и адаптации к новым условиям той реальности, которая создалась в результате глобальной пандемии коронавируса. Наступило осознание того, что посткоронавирусный мир уже не будет прежним, что он более опасен, неопределенен и турбулентен, чем это воспринималось, что мир не просто поразила страшная вирусная инфекция, унесшая много человеческих жизней - произошел кардинальный разворот в развитии человеческой цивилизации, вдруг осознавшей всю глубину и масштаб не только данной коронавирусной ситуации, но и возможных в будущем явлений планетарного масштаба, как оказалось, непрогнозируемых и слабо управляемых. Нет гарантий, что но- 
вая эпидемия (в результате коронавируса или иного заболевания) не разразится в любой момент, начавшись в любом уголке глобального мира и снова поставив под угрозу бизнес, выстроенный на социокультурных, экономических, поведенческих моделях общества, не готового к подобного рода катастрофам планетарного масштаба, не готового по сути к самой глобализации, которая уже стала очевидной реальностью.

Режим самоизоляции и угрозы коронавирусной инфекции стал фактором, значительно сказавшимся на массовом сознании, социальном поведении, будущих моделях организации социальной (образовательной, трудовой, досуговой и др.) жизни. Реакцией на коронавирус и его риски в режиме самоизоляции стал масштабный переход на онлайн практики в самых различных сферах жизнедеятельности и отраслях производства, в том числе и в бизнес-сфере. Их апробация показала возможность использования онлайн-технологий для организации дистанционного режима трудовой деятельности в самых различных сферах, а их адаптивность к рискам типа пандемии сделала их самыми актуальными в перспективе дальнейшей организации производственно-трудовой деятельности, особенно в сферы услуг.

Такой (коронакризисный) поворот в социальной организации современного мира ставит множество вопросов, начиная от осмысления новой (информационной, цифровой) парадигмы подготовки профессиональных кадров для различных отраслей экономики, в том числе бизнес-деятельности, до возможных последствий экзистенциального характера, связанных с перекодировкой общества в режиме технологизации, цифровизации, онлайнизации, атомизации, дегуманизации, т.е. несущих угрозу утраты собственно человеческого в природе постпандемического общества. А пока на уровне массового сознания и научной полемики осмысливаются события и последствия коронавирусного периода истории страны и человечества со сценариями постпандемического мира [20] и перспективами выхода из коронакризиса [21], малый бизнес в России продолжает лихорадить. Сильный удар, нанесенный пандемией коронавируса, остро поставил перед оставшимися в малом бизнесе предприятиями вопрос выживания. Это может негативно сказаться на его социальной репутации ввиду масштабного сокращения сектора малого бизнеса в экономической структуре российского общества, а значит - и социальной полезности, которая, как следует из приведенных эмпирических источников, выступала основой положительных репутационных оценок российского малого бизнеса в докоронавирусный период.

\section{Литература}

1. Лейбин В. Стабильность vs репутация// Отечественные записки. - 2014. №1 [Электронный ресурс]. - Режим доступа: https://magazines.gorky.media/oz/2014/1/ stabilnost-vs-reputacziya.html.

2. Волков Д., Гончаров С., Снеговая М. Как заниматься бизнесом в России [Электронный ресурс]. - Режим доступа: https://www. levada.ru/cp/wp-content/uploads/2020/03/ Otchet-Kak-Delat-Biznes-2020-1.pdf.

3. Паньков В. Смена поколений: как меняетсяпортретроссийскогопредпринимателя [Электронный ресурс]. - Режим доступа: https:// plus.rbc.ru/news/5dede4257a8aa9295986a83d.

4. Махмутов Т.А. Как коронавирус меняет работу малого и среднего бизнеса: закрытие магазинов, поддержка государства и время стартапов [Электронный ресурс]. - Режим доступа: https://ach.gov.ru/ news/kak-koronavirus-menyaet-rabotu-malogoi-srednego-biznesa-zakrytie-magazinovpodderzhka-gosudarstva-i.

5. Волков Ю. Г., Курбатов В.И. Глобальная социология пандемии: отечественные и зарубежные сценарии и тренды послекоронавирусного мира // Гуманитарий Юга России. - 2020. - Т. 9. - №2. С. - 17-32.

6. Парсонс T. Социальные системы // Вопросы социальной теории. - 2008. T. II. - Вып. 1 (2). - C. 38-71.

7. Parsons T. Analytical Approach to the Theory of Social Stratification // American Journal of Sociology. — 1940. — Vol. 45. Pp. 841-862.

8. Шовен П.-М. Социология репутаций [Электронный pecypc]. - Режим доступа: https://magazines.gorky.media/oz/2014/1/ socziologiya-reputaczij.html.

9. Айзенеггер $M$. Доверие и репутация в эпоху глобализации // Отечественные за- 
писки. - 2014. - №1. [Электронный ресурс]. - Режим доступа: https://magazines. gorky.media/oz/2014/1/doverie-i-reputacziya-vepohu-globalizaczii.html.

10. Казаков М.A. Персонификация как тенденция современного политического лидерства: особенности проявления и восприятия // Вестник Нижегородского университета им. Н.И. Лобачевского. Серия: Социальные науки. - 2018. - №1 (49). - С. 54-61.

11. Романович Н.A. К вопросу о персонификации власти в России // Власть. 2009. 一 №9. - С. 13-16.

12. Докукина Е.Ю. Репутация личности: социальные и деловые аспекты: Дис. ... канд. социол. наук. - Ростов-на-Дону, 2004. - 150 с.

13. Малахов $\Phi . В$. Роль репутации организации и ее изучение в период мирового финансового кризиса // Известия высших учебных заведений. Поволжский регион. 2009. - №2 (10). - С. 101-107.

14. Овруцкий A.B. Репутация. Репутационный дискурс. Репутационный ущерб// Психолог. - 2016. - №4. - С. 10-18. [Электронный ресурс]. - Режим доступа: https://nbpublish.com/library_read_article. php?id=19631.

15. Дятлов А.В., Верещчагина А.В., Самьгин С.И. Предпринимательство и экономическая безопасность России в условиях вызовов информационной эпохи: теоретические аспекты социологической рефлексии// Гуманитарные, социально-экономические и общественные науки. — 2015. — №11/3. С. 71-74.

16. Алейников А. В. К проблеме политикосоциологического анализа генезиса российского бизнеса // Власть. - 2008. - №5. C. 9-14.

17. Баринова В. Дыра в ВВП: чем грозит экономике гибель малого бизнеса в России [Электронный ресурс]. - Режим доступа: https://www.forbes.ru/biznes/399389-dyra-vvvp-chem-grozit-ekonomike-gibel-malogobiznesa-v-rossii.

18. «Опора России» предложила создать реестр закрывшихся МСП [Электронный pecypc]. - Режим доступа: https://tass.ru/ $\mathrm{msp} / 8698337$.

19. Как в регионах России бизнес переориентировался после введения карантина [Электронный ресурс]. - Режим доступа: https:// expert.ru/2020/06/15/kak-pereorientirovatbiznes-po-itogam-pandemii-koronavirusa/.

20. Багдасарян В. Коронавирусный мир: постпандемические модели [Электронный ресурс]. - Режим доступа: http:// www.noravank.am/rus/articles/detail.php? ELEMENT_ID $=18066$.

21. Коронакризис-2020: что будет и что делать? Сценарии развития и меры экономической политики / под ред. К. Рогова. - Mocква: Либеральная миссия, 2020. — 45 с.

\section{References}

1. Lejbin V. Stabil'nost' vs reputacija [Stability vs reputation] // Otechestvennye zapiski. 2014. - №1 [Jelektronnyj resurs]. — URL: https://magazines.gorky.media/oz/2014/1/stabilnost-vs-reputacziya.html.

2. Volkov D., Goncharov S., Snegovaja M. Kak zanimat'sja biznesom $\mathrm{v}$ Rossii [How to do business in Russia] [Jelektronnyj resurs]. — URL: https:// www.levada.ru/cp/wp-content/uploads/2020/03/ Otchet-Kak-Delat-Biznes-2020-1.pdf.

3. Pan'kov $V$. Smena pokolenij: kak menjaetsja portret rossijskogo predprinimatelja [Change of generations: how the portrait of the Russian entrepreneur changes] [Jelektronnyj resurs]. — URL: https://plus.rbc.ru/ news/5dede4257a8aa9295986a83d.

4. Mahmutov T.A. Kak koronavirus menjaet rabotu malogo i srednego biznesa: zakrytie magazinov, podderzhka gosudarstva i vremja startapov [How the coronavirus changes the work of small and medium-sized businesses: closing stores, state support and startup time] [Jelektronnyj resurs]. — URL: https://ach.gov. ru/news/kak-koronavirus-menyaet-rabotu-malogo-i-srednego-biznesa-zakrytie-magazinov-podderzhka-gosudarstva-i.

5. Volkov Ju. G., Kurbatov V.I. Global'naja sociologija pandemii: otechestvennye i zarubezhnye scenarii i trendy poslekoronavirusnogo mira [Global sociology of the pandemic: domestic and foreign scenarios and trends of the postcoronavirus world] // Gumanitarij Juga Rossii [Humanities of the South of Russia]. - 2020. Vol. 9. - №2. Pp. - 17-32.

6. Parsons T. Social'nye sistemy [The Social systems] // Voprosy social'noj teorii [Questions of social theory]. - 2008. - Vol. II. - Issue 1(2). - Pp. 38-71. 
7. Parsons T. Analytical Approach to the Theory of Social Stratification // American Journal of Sociology. - 1940. - Vol. 45. Pp. 841-862.

8. Shoven P.-M. Sociologija reputacij [Sociology of reputations] [Jelektronnyj resurs]. URL: https://magazines.gorky.media/oz/2014/1/ socziologiya-reputaczij.html.

9. Ajzenegger M. Doverie i reputacija v jepohu globalizacii [Trust and reputation in the era of globalization] // Otechestvennye zapiski. 2014. — №1. [Jelektronnyj resurs]. — URL: https://magazines.gorky.media/oz/2014/1/doveriei-reputacziya-v-epohu-globalizaczii.html.

10. Kazakov M.A. Personifikacija kak tendencija sovremennogo politicheskogo liderstva: osobennosti projavlenija i vosprijatija [Personification as a trend of modern political leadership: features of manifestation and perception] // Vestnik Nizhegorodskogo universiteta im. N.I. Lobachevskogo. Serija: Social'nye nauki [Bulletin of the Lobachevsky University of Nizhny Novgorod. Series: Social Sciences]. — 2018. №1 (49). - Pp. 54-61.

11. Romanovich N.A. K voprosu o personifikacii vlasti $\mathrm{v}$ Rossii [On the question of personification of power in Russia] // Vlast' [Power]. — 2009. — №9. — Pp. 13-16.

12. Dokukina E. Ju. Reputacija lichnosti: social'nye i delovye aspekty [Personal Reputation: social and business aspects: Ph. D. (Sociology) diss.]. - Rostov-on-Don, 2004. - 150 p.

13. Malahov F. $V$. Rol' reputacii organizacii i ee izuchenie $v$ period mirovogo finansovogo krizisa [The role of the organization's reputation and its study during the global financial crisis] // Izvestija vysshih uchebnyh zavedenij. Povolzhskij region [News of higher educational institutions. Volga region]. — 2009. — №2 (10). Pp. 101-107.

14. Ovruckij A.V. Reputacija. Reputacionnyj diskurs. Reputacionnyj ushherb [Reputation. Reputation discourse. Reputational damage] // Psiholog [Psychologist]. — 2016. — №4. Pp. 10-18. [Jelektronnyj resurs]. - URL: https://nbpublish.com/library_read_article. php?id=19631.
15. Djatlov A. V., Vereshhagina A. V., Samygin S. I. Predprinimatel'stvo i jekonomicheskaja bezopasnost' Rossii v uslovijah vyzovov informacionnoj jepohi: teoreticheskie aspekty sociologicheskoj refleksii [Entrepreneurship and economic security of Russia in the context of challenges of the information age: theoretical aspects of sociological reflection] // Gumanitarnye, social'no-jekonomicheskie i obshhestvennye nauki [Humanities, socio-economic and social Sciences]. - 2015. — №11/3. - Pp. 71-74.

16. Alejnikov $A$. $V$. K probleme politiko-sociologicheskogo analiza genezisa rossijskogo biznesa [On the problem of political and sociological analysis of the Genesis of Russian business]// Vlast' [Power]. — 2008. — №5. - Pp. 9-14.

17. Barinova $V$. Dyra v VVP: chem grozit jekonomike gibel' malogo biznesa $\mathrm{v}$ Rossii [Hole in GDP: what threatens the economy with the death of small business in Russia] [Jelektronnyj resurs]. - URL: https://www.forbes. $\mathrm{ru} /$ biznes/399389-dyra-v-vvp-chem-grozitekonomike-gibel-malogo-biznesa-v-rossii.

18. «Opora Rossii» predlozhila sozdat' reestr zakryvshihsja MSP [«Opora Russia» suggested creating a register of closed SMEs] [Jelektronnyj resurs]. — URL: https://tass.ru/msp/8698337.

19. Kak v regionah Rossii biznes pereorientirovalsja posle vvedenija karantina [How in the regions of Russia business reoriented after the introduction of quarantine] [Jelektronnyj resurs]. - URL: https://expert.ru/2020/06/15/ kak-pereorientirovat-biznes-po-itogam-pandemii-koronavirusa/.

20. Bagdasarjan $V$. Koronavirusnyj mir: postpandemicheskie modeli [Coronavirus world: postpandemic models] [Jelektronnyj resurs]. URL: http://www.noravank.am/rus/articles/detail.php? ELEMENT ID=18066.

21. Koronakrizis-2020: chto budet i chto delat'? Scenarii razvitija i mery jekonomicheskoj politiki [Coronacrisis 2020: what will happen and what to do? Scenarios of development and measures of economic policy] / In K. Rogov (ed.). - Moscow: Liberal'naja missija, 2020. $45 \mathrm{p}$. 


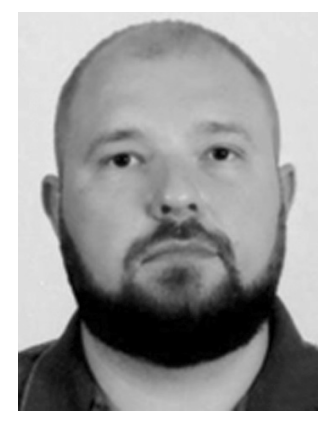

Чернов Кирилл Александрович - аспирант Южно-Российского государственного политехнического университета (НПИ) имени М.И. Платова.

Chernov Kirill Alexandrovich - Postgraduate Student, Platov South Russian State Polytechnic University (NPI).

346428 , г. Новочеркасск, ул. Просвещения, 132

132 Prosveshcheniya st., 346528, Novocherkassk, Russia

E-mail: kirillingeo@mail.ru 